\title{
Why are idioms recognized fast?
}

\author{
Patrizia Tabossi, Rachele Fanari, and Kinou Wolf \\ University of Trieste, Trieste, Italy
}

\begin{abstract}
It is an established fact that idiomatic expressions are fast to process. However, the explanation of the phenomenon is controversial. Using a semantic judgment paradigm, where people decide whether a string is meaningful or not, the present experiment tested the predictions deriving from the three main theories of idiom recognition - the lexical representation hypothesis, the idiom decomposition hypothesis, and the configuration hypothesis. Participants were faster at judging decomposable idioms, nondecomposable idioms, and clichés than at judging their matched controls. The effect was comparable for all conventional expressions. The results were interpreted as suggesting that, as posited by the configuration hypothesis, the fact that they are known expressions, rather than idiomaticity, explains their fast recognition.
\end{abstract}

Idiomatic expressions (e.g., kick the bucket) belong to the vast family of multiword conventional expressions. They are characterized by the fact that their meaning is not a direct function of the meanings of their constituent words: The composition of kick, the, and bucket does not produce "die suddenly." These expressions, which defy the standard compositional view of language comprehension and production, are very common. In fact, speakers show a strong propensity to "speak idiomatically unless there is a good reason not to do so" (Searle, 1975). Thus, understanding how people deal with idiomatic expressions is a crucial part of any theory of language processing.

So far, psycholinguistic research has concentrated primarily on how idiomatic expressions are recognized in their citation form, and much empirical work has been done on the issue. A standard paradigm in this line of investigation is the semantic judgment task: Participants are visually presented with a string of words, and their task is to decide as quickly and accurately as possible whether the string makes sense or not. In addition to strings that do not make sense (e.g., wish out table), idiomatic strings (e.g., break the ice) and matched literal expressions (e.g., break the glass) are presented. One very robust finding is that idiomatic expressions are typically responded to as fast or faster than matched literal expressions are (Gibbs, 1980; McGlone, Glucksberg, \& Cacciari, 1994; Ortony, Schallert, Reynolds, \& Antos, 1978; Swinney \& Cutler, 1979). All current models of idiom recognition must, and indeed do, explain this phenomenon (referred to as the idiom superiority effect); however, they do so in very different ways. The goal of the experiment reported here is to compare the merits of these alternative explanations, thus testing the empirical appropriateness of the alternative models.

The first and probably best known model is the lexical representation hypothesis (LRH; Swinney \& Cutler,
1979). It emphasizes the fact that the meaning of an idiomatic string is arbitrary with respect to its component elements. Because of their lack of semantic compositionality, idioms are mentally represented as long, morphologically complex words, and are recognized through the same retrieval processes that take place during word recognition. The retrieval process is initiated as soon as the first word of an idiomatic string is encountered and runs parallel to the computation of the literal meaning of the expression. However, computing is a slower process than retrieving. Therefore, the idiomatic meaning of a string typically becomes available to the reader before its literal meaning. More generally, recognizing an idiom is faster than computing the meaning of compositional, "literal" expressions.

A more recent model is the so-called idiom decomposition hypothesis (IDH; Gibbs, Nayak, \& Cutting, 1989), which holds that idioms are represented and processed differently, depending on whether they are decomposable or nondecomposable. Semantic compositionality refers to the fact that the constituents of some idioms "carry identifiable parts of the idiomatic meaning" (Nunberg, Sag, \& Wasow, 1994, p. 496). In pop the question, for example, there is a clear correspondence between pop and question and the relevant parts of the figurative meaning "propose marriage." In other idioms, however, there is no such correspondence. For example, there is no sense in which kick and bucket correspond to parts of the meaning of "die suddenly." Idioms like pop the question are decomposable, whereas idioms like kick the bucket are nondecomposable. According to the IDH, idiom processing is based on compositionality; semantically decomposable expressions may be analyzed compositionally. Each component is retrieved from the mental lexicon and combined with the other components of the string according to their syntactic relations. In contrast, the meaning of nondecomposable idioms is retrieved directly from the lexicon. Thus,

P. Tabossi, tabossi@units.it 
the comprehension of decomposable and nondecomposable idioms is achieved through different processes: Decomposable idioms involve the same mechanisms of lexical retrieval and syntactic parsing taking place during the comprehension of literal expressions, whereas nondecomposable idioms require processes akin to those operating in the recognition of individual words (Gibbs, Nayak, Bolton, \& Keppel, 1989). The IDH posits that only compositional expressions are fast. This is because the results of the linguistic analysis are consistent with the idiomatic meaning, facilitating recognition. For nondecomposable idioms, the advantage is not observed because the results of the linguistic analysis conflict with the idiomatic meaning, making recognition more difficult.

The third current model of idiom recognition is the configuration hypothesis (CH; Cacciari \& Tabossi, 1988). According to this view, both decomposable and nondecomposable idioms are represented in the lexicon as configurations of words. Identification processes of verbal idioms are nonlexical in nature and involve mechanisms that typically operate at the sentential level. Idiomatic meanings are associated with configurations of words, the same words that are retrieved from the mental lexicon during literal speech processing. An idiom occurring in discourse is processed literally until enough information builds up in the string to render the idiom recognizable as a memorized expression. Only then is its figurative meaning retrieved.

In this perspective, there is nothing inherent to idioms that makes them fast to recognize. Aside from idiomaticity, the major difference between idiomatic and literal expressions is that idiomatic strings are known to speakers and listeners, whereas literal strings may be entirely novel. This is not to say that literal language is always novel; in fact, some expressions are, but others may be so familiar and predictable as to have become formulaic. However, in the studies assessing speed of idiom processing, the matched literal sentences with which idiomatic expressions are compared are typically fairly novel, whereas idioms are typically very familiar. One way to capture this distinction is to note that the two types of expressionsidioms and controls - differ in terms of familiarity, a variable well known to influence the processing of both individual words and idioms (Connine, Mullennix, Shernoff, \& Yelen, 1990; Gernsbacher, 1984; Schweigert, 1986). Obviously, not all idioms are equally familiar; some are more familiar than others, and there is evidence that more familiar idioms are processed faster than less familiar ones are (Cronk, Lima, \& Schweigert, 1993; Cronk \& Schweigert, 1992). Unfortunately, in the early studies that established the idiom superiority effect, familiarity of the idiomatic strings is not always available (Gibbs, 1980;
Ortony et al., 1978; Swinney \& Cutler, 1979). However, inspection of the materials, when possible, suggests that the idiomatic strings are typically very familiar (Swinney \& Cutler, 1979). Also, in more recent studies reporting the effect, familiar idioms have been consistently used (McGlone et al., 1994; Tabossi, Fanari, \& Wolf, 2008). In light of these considerations, the $\mathrm{CH}$ assumes that the advantage that idioms exhibit over literal counterparts is largely determined by familiarity, whereas idiomaticity per se has no role.

In order to test the validity of these alternative explanations, we asked Italian participants to perform a semantic judgment task on a series of expressions. The test expressions were all meaningful and consisted of familiar formulaic expressions or matched literal controls. The formulaic expressions were all very familiar. They were literal and nonliteral decomposable idioms, literal and nonliteral nondecomposable idioms, and clichés. Test materials are illustrated in Table 1.

Clichés are multiword conventional expressions such as conquer the world or any friend of yours is a friend of mine. Like idioms, compounds (e.g., frequent flyer program), names (e.g., Count Dracula), and titles (e.g., Gone With the Wind) are part of the large body of linguistic formulae known to speakers (Wray, 2002), and are typically characterized as regular phrasal expressions, just like any literal phrase, with no syntactic or semantic anomaly. What sets apart clichés from literal expressions is that they occur so frequently in the language as to become trivial, whereas what sets them apart from idioms is that they are compositional (Casadei, 2001; Kirkpatrick, 1996). In fact, their full compositionality is the criterion used by Jackendoff (1995) to distinguish clichés from idioms: "The Wheel of Fortune (WoF) corpus consists mostly of phrases, of all sorts.... There are clichés (which I distinguish from idioms because they apparently have nothing noncompositional in their syntax or meaning)" (p. 135). The meaning of conquer the world, for instance, is what results from combining conquer, the, and world, according to syntax. This is very different from what happens with idioms, where beat, around, the, and bush, syntactically combined, for example, in no way produce "hesitate."

It is interesting that, like idioms, clichés are known expressions, but, unlike idioms, they are compositional: Depending on how the three theories of idiom recognition explain the idiom superiority effects, it is possible to derive different predictions on whether and under what conditions idioms and clichés should exhibit the same facilitation effects over literal control expressions.

As noted above, according to LRH idioms are mentally represented and processed as individual words, and

Table 1 An Example of the Conventional Expressions Used in the Experiment

\begin{tabular}{ll}
\hline Decomposable literal idiom & Andare in fumo-go up in smoke-come to nothing \\
Decomposable nonliteral idiom & Confondere le acque-confuse the waters-create confusion on purpose \\
Nondecomposable literal idiom & Essere al fresco-be at the fresh-be in jail \\
Nondecomposable nonliteral idiom & Andare a genio-go to genius-be pleasant \\
Cliché & Maneggiare con cura-handle with care \\
\hline
\end{tabular}


their speed of recognition relative to comparable literal expressions is because their meaning is retrieved rather than computed. This is the case for both decomposable and nondecomposable idioms, since the LRH does not distinguish between the two. According to the LRH, idioms and other expressions are represented and processed holistically because they are noncompositional (Swinney \& Cutler, 1979):

The analysis we have applied to idiom processing is the same analysis that we would presumably wish to apply to certain other complicated language forms. For example, one might well expect comprehension of nominal compounds (shrimpboat, hotdog) to occur through lexical representation and access. ... As a great number of nominal compounds are not ... a simple combination of the literal meanings of their component morphemes, they present a problem similar to that provided by idioms for the comprehension device. (p. 533)

It follows from the above assumption that expressions that are compositional, however well known they are, are processed analytically. Clichés are precisely expressions of this sort; although they may be very well known, they are literal, and their meaning is fully compositional. Therefore, according to the LRH, nothing in them calls for retrieval rather than computational processes. Undoubtedly, the fact that clichés are known expressions affects their recognition, and it is likely that the computation processes underlying their comprehension are faster than the computation processes underlying the comprehension of novel expressions. However, retrieval and computing are qualitatively different processes, and a fast computation should still be slower than retrieval. Therefore, the LRH predicts that both decomposable and nondecomposable idioms are equally faster than their literal counterparts. Clichés may be faster than their literal counterparts, but, if so, their difference should be reliably smaller than the difference between idioms and their controls.

The IDH posits that decomposable expressions are fast because the results of the linguistic analysis are consistent with the idiomatic meaning, and hence facilitate recognition. For nondecomposable idioms the advantage is not observed, because the results of the linguistic analysis conflict with the idiomatic meaning, making recognition more difficult. Clichés are entirely compositional, and from this perspective they should behave like decomposable idioms: Both should produce faster responses than their controls, unlike nondecomposable idioms, which should in fact be slower.

Finally, in the $\mathrm{CH}$, decomposable and nondecomposable idioms are processed in the same way. Idioms are faster than literal expressions because they are well known, and their syntax and semantics have no role in the phenomenon (Tabossi \& Zardon, 1995). In this view, all expressions, if they are well known, are easier to process than novel expressions, and whether they are compositional or not is not relevant in determining processing time. Accordingly, the $\mathrm{CH}$ predicts that familiar decomposable idioms, familiar nondecomposable idioms, and familiar clichés should all be equally faster than matched control expressions.

\section{METHOD}

\section{Participants}

Thirty-six undergraduates, all speakers of Italian, volunteered in the experiment. They had normal or corrected-to-normal vision and were unaware of the purposes of the research.

\section{Materials}

There were 48 familiar verbal expressions: 16 decomposable idioms ( 8 literal and 8 nonliteral), 16 nondecomposable idioms ( 8 literal and 8 nonliteral), and 16 clichés.

The idiomatic expressions were selected as follows. A total of 160 idioms in which the verb was followed by a noun phrase or a preposition phrase were selected from the Dizionario dei modi di dire della lingua italiana (Dictionary of the ways of saying things in the Italian language) (Quartu, 2000). We chose idioms that we believed to be familiar, half literal and half nonliteral. Intuitions on literality were tested by asking 10 judges, all native speakers of Italian, to decide for each expression whether it might have a plausible meaning other than the figurative one. There was $100 \%$ agreement among the judges that 80 idioms had a literal interpretation and 80 had not.

A new panel of 19 judges was used to evaluate semantic analyzability. Judges were given a booklet containing written instructions, along with a list of idiom-paraphrase pairs in random order. The instructions required them to determine to what extent the components of each expression singularly contributed to the figurative meaning of the expression as expressed in the paraphrase. For this judgment, they had to use a 7-point scale, where 1 was not at all similar and 7 very similar. The mean compositionality rating was $3.82(S D=$ 1.12). From the initial idioms, we selected 16 decomposable expressions (mean compositionality rating $4.53, S D=0.68$ ) and 16 nondecomposable expressions (mean compositionality rating 3.01 , $S D=0.21)$. The difference in compositionality was statistically reliable $[t(30)=9.25, p=.0001]$.

Sixteen clichés, evaluated as highly familiar by three expert judges, were also selected. They were chosen from an initial corpus of 115 expressions, collected from 30 Italian speakers, who were asked to produce as many "known sentences" as they could. Three examples were given. One example (Vi dichiaro marito e moglie/ I declare you husband and wife) was the expression typically used at the end of a marriage ceremony; one example was the title of a famous film (Gli Uomini Preferiscono le Bionde/Gentlemen Prefer Blondes); the last example was a sentence frequently heard or read (E'vietato parlare al conducente/It is forbidden to speak to the driver). In selecting the test expressions, in addition to familiarity, and in agreement with the definition of cliché, we paid attention to the following criteria: All the expressions were well-formed sentences, they meant nothing more than what they stated, and they did not appear to have syntactic restrictions.

Each conventional expression was paired with a meaningful and syntactically acceptable literal expression, matched for number of words and letters (see Table 2). As for words, clichés (conventional and control) were longer than decomposable and nondecomposable idioms, which did not differ from one another $[F(2,45)=13.24$, $\left.M S_{\mathrm{e}}=0.68, p=.0001, \eta^{2}=.370\right]$ : clichés versus decomposable idioms (Scheffé test, $p<.0001$ ); clichés versus nondecomposable idioms (Scheffé test, $p<.0001$ ); and decomposable versus nondecomposable idioms (Scheffé test, $p=.98$ ). Conventional strings did not differ reliably from controls $\left[F(1,45)=0.32, M S_{\mathrm{e}}=0.033, p=\right.$ $\left..57, \eta^{2}=.007\right]$, and there was no reliable interaction $[F(2,45)=$ $\left.0.32, M S_{\mathrm{e}}=0.033, p=.73, \eta^{2}=.014\right]$.

Similar results were obtained for number of letters. Again, clichés were reliably longer than decomposable and nondecomposable idioms, which did not differ from one another $\left[F(2,45)=9.62, M S_{\mathrm{e}}=\right.$ $17.89, p<.001, \eta^{2}=.299$ ]: clichés versus decomposable idioms (Scheffé test, $p=.003$ ); clichés versus nondecomposable idioms 
Table 2

Mean Number of Words and Letters, and Standard Deviations, for the Conventional and Control Expressions in the Three Groups of Materials

\begin{tabular}{|c|c|c|c|c|}
\hline & \multicolumn{2}{|c|}{ Words } & \multicolumn{2}{|c|}{ Letters } \\
\hline & $M$ & $S D$ & $M$ & $S D$ \\
\hline \multicolumn{5}{|c|}{ Decomposable Literal Idioms } \\
\hline Conventional expressions & 2.79 & 0.65 & 14.10 & 3.53 \\
\hline Control expressions & 2.83 & 0.70 & 13.46 & 3.55 \\
\hline \multicolumn{5}{|c|}{ Decomposable Nonliteral Idioms } \\
\hline Conventional expressions & 2.80 & 0.76 & 13.99 & 4.16 \\
\hline Control expressions & 2.78 & 0.73 & 13.94 & 3.60 \\
\hline \multicolumn{5}{|c|}{ Clichés } \\
\hline Conventional expressions & 3.87 & 0.95 & 18.75 & 4.23 \\
\hline Control expressions & 3.87 & 0.95 & 18.50 & 4.46 \\
\hline
\end{tabular}

(Scheffé test, $p=.004)$; and decomposable versus nondecomposable idioms (Scheffé test, $p=.99$ ). Conventional and control strings did not differ $\left[F(1,45)=1.96, M S_{\mathrm{e}}=1.20, p=.17, \eta^{2}=.041\right]$, and the interaction was not reliable $\left[F(2,45)=0.55, M S_{\mathrm{e}}=1.20, p=\right.$ $\left..58, \eta^{2}=.023\right]$.

Control strings were obtained by replacing the first one or two words of the conventional strings with new words. When two words were replaced, one word was always a function word-typically, a determiner or a preposition (e.g., Essere al fresco/Be at the freshSentire il fresco/Feel the fresh). Never more than one content word was changed. The original content words (e.g., essere) and their substitutes (e.g., sentire) were matched for number of letters (see Table 3). Three $t$ tests showed that, in fact, the original and substitute words did not statistically differ for this dimension: for decomposable idioms $\left[t(15)=1.72, p=.11, \eta^{2}=.247\right]$; for nondecomposable idioms $\left[t(15)=0.32, p=.76, \eta^{2}=.011\right]$; or for clichés $[t(15)=$ $\left.1.73, p=.10, \eta^{2}=.249\right]$. Original and substitute words were also matched for frequency (Bortolini, Tagliavini, \& Zampolli, 1972; see Table 3), and three $t$ tests assessed that nonreliable differences in frequency existed between them: decomposable idioms $[t(15)=1.44$, $\left.p=.17, \eta^{2}=.187\right]$; nondecomposable idioms $[t(15)=1.19, p=$ $\left..25, \eta^{2}=.136\right]$; and clichés $\left[t(15)=0.37, p=.71, \eta^{2}=.015\right]$.

Moreover, to ensure that the different words in the conventional and control strings did not differ in the ease with which they were recognized, they were inserted in a list. Since some words were repeated in more than one expression, the number of words was 72 rather than 96 (48 from the conventional strings and 48 from the control strings). The list contained 72 words and 72 legal pseudowords. Two blocks of 72 items each-36 words and 36 pseudowords - were created. Within blocks, items occurred in random order. The two blocks were presented in a balanced order to 12 Italian participants, who were requested to perform a lexical decision task. The mean response times (RTs) to the words in the decomposable idioms, in the nondecomposable idioms, and in the clichés were compared with responses to their matched substitutes in the control strings by means of three $t$ tests. The results were the following: For decomposable idioms $\left[t(15)=0.19, p=.84, \eta^{2}=.004\right]$; for the nondecomposable idioms $\left[t(15)=1.22, p=.24, \eta^{2}=.142\right]$; and for clichés $[t(15)=$ $\left.0.89, p=.38, \eta^{2}=.081\right]$. The mean RTs and $S D$ s for the various groups of words are reported in Table 3.

A final test was conducted to assess the familiarity of the conventional and control strings. To this end, a further panel of 20 undergraduates, all native Italian speakers, received a list of all the expressions, conventional and control, in random order. The list included 96 expressions. The instructions specified that the task was to evaluate for each expression whether participants thought that the expression was known to students like them (Connine et al., 1990; Gernsbacher, 1984). They had to give their evaluation using a 7-point scale, where
1 meant not at all known and 7 meant very well known. Mean scores for the different types of strings are reported in Table 4.

Two ANOVAs, one by participants and one by items, were conducted to compare the familiarity of the three types of conventional strings and their controls. There were two independent variables: type of expression (decomposable idioms vs. nondecomposable idioms vs. clichés) and type of string (conventional vs. control). In the analysis by participant, both variables were within subjects; in the item analysis, type of expression was between subjects and type of string was within subjects. The results showed only a main effect of type of string $\left[F_{1}(1,19)=250.82, M S_{\mathrm{e}}=0.87, p<.0001, \eta^{2}=\right.$ $\left..774 ; F_{2}(1,45)=169.19, M S_{\mathrm{e}}=0.99, p<.0001, \eta^{2}=.784\right]$.

Type of expression was not reliable $\left[F_{1}(2,38)=2.59, M S_{\mathrm{e}}=\right.$ $0.64, p=.088, \eta^{2}=.012 ; F_{2}(2,45)=1.79, M S_{\mathrm{e}}=1.22, p=.18$, $\left.\eta^{2}=.074\right]$. The interaction was also not reliable $\left[F_{1}(2,38)=2.21\right.$, $M S_{\mathrm{e}}=0.46, p=.12, \eta^{2}=.007 ; F_{2}(2,45)=0.84, M S_{\mathrm{e}}=0.99, p=$ $\left.0.44, \eta^{2}=.008\right]$. Conventional strings were judged more familiar than were control strings, and this difference was observed for all three types of expressions, as established by means of planned comparisons: decomposable idioms versus controls $\left[F_{1}(1,19)=90.92\right.$, $\left.M S_{\mathrm{e}}=0.60, p<.0001 ; F_{2}(1,45)=43.42, M S_{\mathrm{e}}=0.99, p<.0001\right]$; nondecomposable idioms versus controls $\left[F_{1}(1,19)=123.33\right.$, $\left.M S_{\mathrm{e}}=0.71, p<.0001 ; F_{2}(1,45)=70.89, M S_{\mathrm{e}}=0.99, p<.0001\right]$; and clichés versus controls $\left[F_{1}(1,19)=163.21, M S_{\mathrm{e}}=0.48, p<\right.$ $\left..0001 ; F_{2}(1,45)=56.54, M S_{\mathrm{e}}=0.99, p<.0001\right]$. Test materials are listed in the Appendix.

In addition, 48 strings were created to be used as fillers. They were comparable for length, structure, and word frequency with the test materials, but were unacceptable (e.g., Il soldo pregano finito/ The coin pray finished). Finally, 14 practice trials conforming to the specifications of the experiment were created.

Two lists of 96 trials each were created. Each contained all the fillers and 48 test items, so that if a conventional expression appeared in one list its control appeared in the other, and vice versa. All types of test materials were equally represented in both lists.

\section{Design and Procedure}

Participants were tested individually. They sat in a soundattenuated room, in front of a Power Mac that controlled the presentation of the experiment and recorded response latencies. Participants were instructed to read each string and to press a button with the dominant hand as soon as they saw a meaningful Italian phrase; otherwise, they had to do nothing. The importance of being both accurate and fast was stressed. After the practice trials, the experiment proper started and lasted about $10 \mathrm{~min}$.

Each string, which appeared in the center of the screen and was preceded by a tone, stayed on the screen until the participant pressed

Table 3

Mean Number of Letters, Mean Frequency, Mean Response Times (RTs, in Milliseconds), and Standard Deviations for the Original and Substituted Words in the Three Groups of Materials

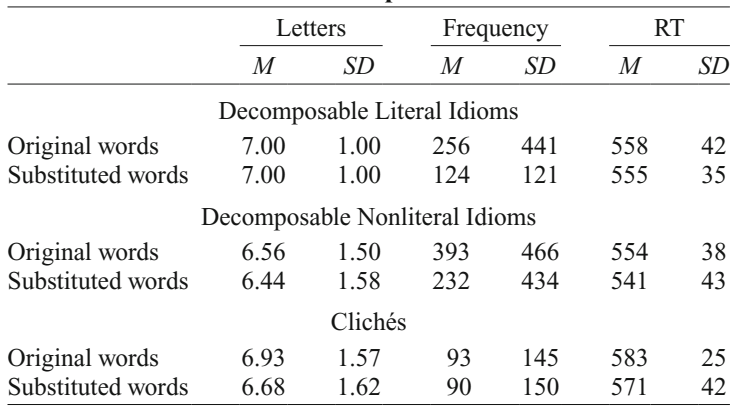


Table 4

Mean Familiarity Scores and Standard Deviations of the Different Conventional and Control Expressions Used in the Study

\begin{tabular}{lccccc}
\hline & \multicolumn{2}{c}{$\begin{array}{c}\text { Conventional } \\
\text { Expressions }\end{array}$} & & \multicolumn{2}{c}{$\begin{array}{c}\text { Control } \\
\text { Expressions }\end{array}$} \\
\cline { 2 - 3 } \cline { 5 - 6 } & $M$ & $S D$ & & $M$ & $S D$ \\
\hline Decomposable idioms & 5.82 & 0.52 & & 3.47 & 1.04 \\
Nondecomposable idioms & 6.04 & 0.48 & & 3.09 & 1.08 \\
Clichés & 6.35 & 0.52 & & 3.55 & 1.15 \\
Overall & 6.05 & 0.66 & & 3.41 & 1.35 \\
\hline
\end{tabular}

Note-The scores were on a 7-point scale, in which 1 meant not at all known and 7 very well known.

a button, or reset automatically after $3 \mathrm{sec}$. There was a 2 -sec delay between trials. Responses were measured from string onset.

An equal number of participants was randomly assigned to each list. There were two independent variables: type of expression (decomposable idioms vs. nondecomposable idioms vs. clichés) and type of string (conventional vs. control).

\section{RESULTS}

Responses over or below 2 SDs from the item-specific overall mean were treated as errors and excluded from analyses. The mean percentage of errors, including outliers, misses, and false alarms, was $1.40 \%$.

Two ANOVAs, one by participants and one by items, were conducted on correct responses. By participants, both variables were within subjects; by items, type of expression was between subjects, and type of string was within subjects.

RTs differed across types of expressions $\left[F_{1}(2,70)=\right.$ $34.96, M S_{\mathrm{e}}=4,354, p<.00 ; F_{2}(2,45)=22.44, M S_{\mathrm{e}}=$ $2,844, p<.00, \eta^{2}=.499$ ] (see Table 5); clichés, conventional and control, produced slower responses than did either decomposable or nondecomposable expressions (Scheffé test, $p<.001$ ). Decomposable and nondecomposable expressions did not differ from one another (Scheffé test, $p \geq .25$ ).

Also, conventional strings were reliably faster than control strings $\left[F_{1}(1,35)=291.16, M S_{\mathrm{e}}=4,273, p<.01\right.$; $\left.F_{2}(1,45)=135.02, M S_{\mathrm{e}}=4,063, p<.01, \eta^{2}=.739\right]$. The mean RTs and SDs in the two types of strings and the effect sizes are reported in Table 6.

The same pattern occurred with decomposable idioms (Scheffé test, $p<.001$ ), nondecomposable idioms (Scheffé test, $p<.001$ ), and clichés (Scheffé test, $p<.001$; see Table 6). The interaction between type of expression and type of string was not reliable either by participants $\left[F_{1}(2,70)=2.48, M S_{\mathrm{e}}=4,980, p=.10, \eta^{2}=.014\right]$ or by items $\left[F_{2}(2,45)=1.30, M S_{\mathrm{e}}=4,063, p=.28, \eta^{2}=.014\right]$.

The results indicate that clichés, whether conventional or control, had longer RTs than decomposable and nondecomposable idioms did. This reflects the fact that the selected clichés, and therefore the control strings they were matched with, were longer, hence slower to respond to, than idioms and matched controls were. However, the relevant point here is not the absolute recognition times of these expressions, but whether conventional strings show an advantage over controls and, if so, how much. The data suggest that decomposable idioms, nondecomposable idioms, and clichés are all faster than controls, and there is no indication that some conventional expressions have a larger or smaller advantage over their controls than do other expressions.

Admittedly, although the analysis by participants indicates that the interaction between type of expression and type of string is not reliable, the $p$ is low $(p=.10)$. Furthermore, whereas the advantage shown by nondecomposable idioms and clichés is almost identical (138 and $135 \mathrm{msec}$, respectively), the difference between decomposable idioms and matched controls is somewhat larger $(182 \mathrm{msec})$. These elements might cast some doubt on the conclusion that all conventional strings have a similar advantage over their controls.

However, in the analysis by items, the $p$ value for the interaction is high $(p=.28)$, suggesting that the trend toward the interaction detected in the analysis by participants is not consistent. Moreover, if the interaction were reliable, it would indicate that decomposable idioms show a greater advantage over their controls than do nondecomposable idioms and clichés, which are identical. This would be inconsistent with all the theories, none of which predicts a similar outcome. In fact, it would be theoretically inexplicable. These statistical and theoretical considerations jointly suggest that the larger advantage shown by the decomposable idioms, which accounts for the unreliable trend observed in the interaction in the analysis by participants, cannot alter the general conclusion that conventional strings are all equally faster than matched literal strings.

\section{DISCUSSION}

The present study was conducted to test the adequacy of the explanations proposed by the three major theories of idiom recognition - the $\mathrm{LRH}$, the IDH, and the $\mathrm{CH}$ - for a well-known phenomenon, the so-called idiom superiority effect. Depending on their assumptions on the representation and processing of idiomatic strings, the three theories make different predictions on how fast decomposable idioms, nondecomposable idioms, and clichés are processed, relative to matched literal expressions. The results showed that all formulaic expressions are faster than their controls, and there is no evidence that the advantage differs from the different types of formulae.

This pattern of findings is not consistent with the predictions of the LRH. According to this theory, all conventional strings are faster than matched control strings, but the advantage of decomposable and nondecomposable

Table 5

Mean Response Times (in Milliseconds), Standard Deviations, and Effect Sizes $\left(\eta^{2}\right)$ of Decomposable Idioms, Nondecomposable Idioms, and Clichés, With Matched Controls

Decomposable Nondecomposable Idioms $\quad$ Idioms $\quad$ Clichés

\begin{tabular}{|c|c|c|c|c|c|c|}
\hline$M$ & $S D$ & $M$ & $S D$ & $M$ & $S D$ & $\eta^{2}$ \\
\hline 964 & 47 & 945 & 36 & 1,032 & 54 & 0.499 \\
\hline
\end{tabular}


Table 6

Mean Response Times (in Milliseconds), Standard Deviations, and Effect Sizes $\left(\eta^{2}\right)$ of the Conventional and Control Strings for the Three Types of Expressions

\begin{tabular}{|c|c|c|c|c|c|}
\hline & \multicolumn{2}{|c|}{ Conventional } & \multicolumn{2}{|c|}{ Control } & \multirow[b]{2}{*}{$\eta^{2}$} \\
\hline & $M$ & $S D$ & $M$ & $\overline{S D}$ & \\
\hline Decomposable idioms & 873 & 28 & 1,055 & 36 & .787 \\
\hline Nondecomposable idioms & 876 & 36 & 1,014 & 22 & .700 \\
\hline Clichés & 965 & 60 & 1,100 & 48 & .634 \\
\hline Overall & 905 & 50 & 1,056 & 58 & .704 \\
\hline
\end{tabular}

idioms must be reliably greater than the advantage shown by clichés. In this view, noncompositional expressions such as idioms and compounds are processed holistically, whereas compositional expressions such as novel expressions and clichés are computed. Conventional expressions are usually familiar, and for this reason they may well be recognized faster than literal, less familiar ones are; however, compositionality rather than familiarity determines whether an expression is retrieved from the lexicon or computed. Since retrieval is faster than computing, idioms should show an advantage over clichés. Such a difference, however, was not observed in the data.

Various lines of research, showing the syntactic and semantic flexibility of idiomatic expressions, have already provided evidence against the LRH (Glucksberg, 2001; McGlone et al., 1994; Van de Voort \& Vonk, 1995). Other studies indicate that the time course of idiom meaning activation, in contrast with the assumptions of the LRH, is different from the time course of activation of the meaning of individual words (Cacciari \& Tabossi, 1988; Tabossi \& Zardon, 1993, 1995). The present findings add to previous results, suggesting that the explanation offered by the LRH for the idiom superiority effect is not correct.

These conclusions hold only insofar as clichés are indeed compositional. If they were not, according to the LRH they would also be represented and processed holistically, and the present results would be perfectly consistent with its claims.

In the absence of a psycholinguistic theory of how clichés are mentally represented and processed, it might be claimed, for instance, that clichés share similar semantic anomalies with idioms: a cliché like conquer the world might not mean "vanquish the planet," but something like "rise to the top of a particular enterprise." In a similar vein, it might be argued that the constituents of clichés lose their semantic value when they enter into the clichés.

As for clichés being semantically anomalous, their characterization rules out that possibility. As pointed out in the beginning of this article, these expressions are distinguished from idioms precisely insofar as they, unlike idioms, are semantically compositional (Jackendoff, 1995; Kirkpatrick, 1996). It is true that clichés are often used metaphorically; hence, conquer the world, for instance, can be interpreted as "rise to the top of a particular enterprise." But the expression does not mean "rise to the top of a particular enterprise," much as fly does not mean "go in a hurry," although in a sentence like "he flew home" it is likely to be interpreted in that way.
Whether the constituents of clichés lose their semantic value - that is, whether or not they are fully processed as individual words when occurring in the cliché-is a different issue. There are various pieces of evidence suggesting that the individual words of conventional expressions are indeed analyzed (Konopka \& Bock, 2009; Peterson, Burgess, Dell, \& Eberhard, 2001; Trueswell \& Kim, 1998; Van de Voort \& Vonk, 1995); we will return to this point later. But even if it should turn out that the individual components of clichés are not fully analyzed during string processing, in these expressions it is still the case that the meaning is the result of the composition of their individual words. Therefore, according to the LRH, clichés are computed, and the predictions derived from this theory hold.

The present data are also at odds with the IDH, since there is no evidence that depending upon semantic analyzability idioms undergo different processes. In particular, contrary to the predictions of the IDH, nondecomposable idioms showed the same advantage as did decomposable idioms and clichés.

Empirical support for the notion that compositionality affects the processing of idioms in their citation form is very scarce, and several studies have failed to replicate the results obtained by Gibbs, Nayak, and Cutting (1989) in either comprehension or production (Cutting \& Bock, 1997; Tabossi et al., 2008; Titone \& Connine, 1994b). Cutting and Bock, for example, explored whether decomposable idioms might be more likely than nondecomposable idioms to give rise to the production of more idiom blends, but failed to find any effect; no difference in the error rates between the two types of expressions was observed. The authors concluded that idioms have identical lexical representations when they enter the production process. Nonetheless, the IDH continues to be viewed favorably in current research (Caillies \& Butcher, 2007; Caillies \& LeSourn-Bissaoui, 2006; Mateu \& Espinal, 2007). Our findings corroborate and extend the evidence against the claim that decomposable and nondecomposable idioms are processed differently. The notion of compositionality as formulated by Nunberg et al. (1994) may be an important one in understanding the syntactic use of idiomatic expressions, but it does not explain how these expressions are recognized in their citation form.

The findings are consistent with the $\mathrm{CH}$, according to which the semantic anomaly of idioms plays no role in determining their advantage over matched controls, and this advantage reflects the ease with which people identify well-known expressions in general, whether idioms, clichés, quotes, or something else (Tabossi \& Zardon, 1995). In this view, a major role in explaining the idiom superiority effect is given to familiarity. However, another important factor that might account for the present results is predictability. This refers to the fact that idioms differ in how quickly the initial part of a string makes the idiomatic conclusion predictable. For example, a sentence like "Harry had to burn the midnight . .." tends to be completed idiomatically with the word oil. Accordingly, burn the midnight oil is considered to be a predictable idiom. In contrast, "Fran tried to make a clean ..." tends to be 
completed literally rather than idiomatically, with sweep. For this reason, make a clean sweep is considered to be nonpredictable. (The examples are taken from Titone \& Connine, 1994a.)

Predictability is known to influence idiomatic processing (Cacciari \& Tabossi, 1988; Tabossi \& Zardon, 1993, 1995; Titone \& Connine, 1994a), and more generally, predictable expressions are processed faster than less predictable ones. Obviously, conventional strings tend to be more predictable than literal strings, particularly when they are fairly long, as with the clichés used here. It is possible, therefore, that the advantage for the conventional strings we observed in the data is due to the predictability rather than to the familiarity of these expressions.

In order to elucidate this point, a predictability test for all the expressions used in the experiment was devised. To this end, the last word of each expression was removed (e.g., arrivare in ... from arrivare in porto/arrive in the harbor, "get to the end"; lasciare il ... from lasciare il porto/leave the harbor), and a panel of 11 Italian speakers was requested to complete with a single word the fragments thus obtained. The strings were presented in written form in random order, preceded by the appropriate instructions. In the scoring, a response was considered predicted if the inserted word matched the one removed, and was considered unpredicted otherwise. The percentages of cases in which the strings were completed with the predicted word for the different types of expressions are reported in Table 7.

An ANOVA by items was conducted on the arcsine transformations of the percentages obtained with two independent variables: type of expression (decomposable idioms vs. nondecomposable idioms vs. clichés) and type of string (conventional vs. control). Type of expression was between subjects, and type of string was within subjects. The results revealed an effect of type of expression $\left[F(2,45)=16.14, M S_{\mathrm{e}}=0.56, p<.0001, \eta^{2}=.418\right]$. Clichés, both conventional and control strings, were more predictable than were decomposable and nondecomposable idioms, both conventional and control strings (Scheffé test, $p<.0001$ ), which did not differ from one another (Scheffé test, $p=.98$ ). Also, conventional expressions were more predictable than were controls $[F(1,45)=$ $\left.34.83, M S_{\mathrm{e}}=0.23, p<.0001, \eta^{2}=.418\right]$. The interaction was not reliable $\left[F(2,45)=1.76, M S_{\mathrm{e}}=0.23, p=.18\right.$, $\left.\eta^{2}=.042\right]$.

Clichés were longer than idioms. It is not surprising, therefore, that they were also more predictable. Equally

Table 7

Mean Percentages of Predictability and Standard Deviations of the Different Conventional and Control Expressions Used in the Study

\begin{tabular}{lccrrr}
\hline & \multicolumn{2}{c}{ Conventional } & & \multicolumn{2}{c}{ Control } \\
\cline { 2 - 3 } \cline { 6 - 7 } & $M$ & $S D$ & & $M$ & \multicolumn{1}{c}{$S D$} \\
\hline Decomposable idioms & 19.32 & 28.53 & & 4.55 & 11.00 \\
Nondecomposable idioms & 23.86 & 26.11 & & 2.48 & 9.22 \\
Clichés & 67.61 & 23.46 & & 31.25 & 38.13 \\
Overall & 36.93 & 33.72 & & 12.88 & 26.51 \\
\hline
\end{tabular}

unsurprising is the fact that conventional strings were more predictable than controls were. This is not to say that they were highly predictable. In fact, their average predictability would be considered low or very low in most of the studies that explored the notion (Cacciari \& Tabossi, 1988; Tabossi, Fanari, \& Wolf, 2005; Tabossi \& Zardon, $1993,1995)$. However, there is a reliable difference between clichés and idioms, and, more importantly, between conventional and control strings. Hence, predictability, rather than familiarity, might explain the present results.

To explore this possibility, we conducted an ANCOVA by items, where RTs were the dependent variable, type of expression and type of string were the independent variables, and predictability was the covariate. The results replicated the initial ANOVA. Type of expression was reliable $\left[F(2,43)=14.90, M S_{\mathrm{e}}=2,907, p<.001, \eta^{2}=.402\right]$. Type of string was also reliable $\left[F(1,43)=31.28, M S_{\mathrm{e}}=\right.$ $\left.4,177, p<.0001, \eta^{2}=.407\right]$. The interaction was not reliable $\left[F(2,43)=0.78, M S_{\mathrm{e}}=4,177, p=.46, \eta^{2}=.020\right]$.

We then conducted the same ANCOVA with familiarity rather than predictability as covariate. The results replicated the effects of type of expression $[F(2,43)=18.29$, $\left.M S_{\mathrm{e}}=2,920, p<.001, \eta^{2}=.455\right]$. However, type of string was no longer reliable $\left[F(1,43)=0.39, M S_{\mathrm{e}}=\right.$ $\left.4,002, p=.53, \eta^{2}=.008\right]$. Again, the interaction was not significant $\left[F(2,43)=1.26, M S_{\mathrm{e}}=4,002, p=.29\right.$, $\left.\eta^{2}=.052\right]$.

In light of these results, it is reasonable to assume that predictability does not have a major role in explaining the present data; once predictability has been taken into account, a clear difference between conventional and control strings is still detected. In contrast, when familiarity is taken care of, RTs to conventional and control strings are no longer reliably different, suggesting that familiarity has indeed a large part in determining the effect.

This conclusion is not particularly surprising, if one considers the relevance that familiarity has in the recognition of individual words (Connine et al., 1990; Gernsbacher, 1984) as well as in the processing of idioms (Cronk et al., 1993; Giora \& Fein, 1999; Schweigert, 1991; Schweigert et al., 2003). It has been shown, for example, that familiarity is one of the variables that render idiomatic expressions a heterogeneous class (Glass, 1983; Schweigert, 1986). Also, familiarity can explain the greater ease with which people typically process literal idiomatic expressions in their figurative rather than literal interpretation (Popiel \& McRae, 1988; Schweigert, 1986). Finally, it is well known that familiarity modulates the processing time of idioms, since highly familiar idioms are processed faster than are less familiar ones (Cronk \& Schweigert, 1992; Schraw, Trathen, Reynolds, \& Lapan, 1988; Schweigert \& Moates, 1988). However, whether low familiarity idioms still exhibit the idiom superiority effect has not yet been clarified, and further research is necessary to assess whether the prediction following from the present hypothesisthat the effect should disappear or be very reduced as familiarity decreases - actually holds.

But investigating familiarity was not the main purpose of this study, whose main concern was to shed light on the nature of the idiom superiority effect and to establish 


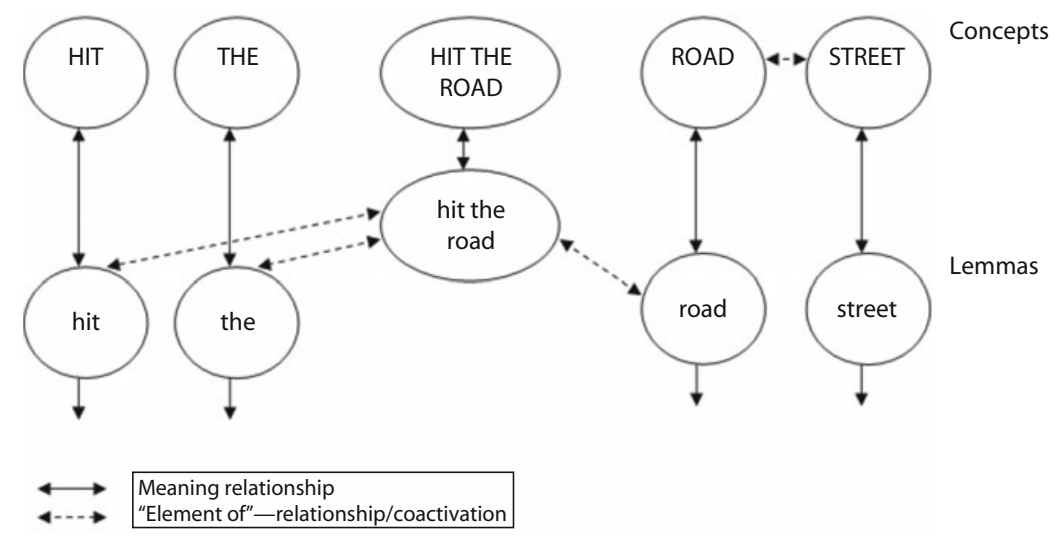

Figure 1. Sprenger, Levelt, and Kempen's (2006) model of idiom production. From "Lexical Access During the Production of Idiomatic Phrases," by S. A. Sprenger, W. J. M. Levelt, and G. Kempen, 2006, Journal of Memory \& Language, 54, p. 176. Copyright 2006 by Elsevier. Adapted with permission.

whether the peculiarities of this type of conventional expression had some role in the phenomenon. The results indicate that, as suggested by Burt (1992), nothing specifically idiomatic determines the speed with which these expressions are processed, as compared with control expressions, since expressions with different characteristics show precisely the same advantage, when familiarity is controlled for.

As we have seen, the findings of this experiment can easily be explained by the $\mathrm{CH}$, but other theories can also account for the results. One such theory is the superlemma hypothesis (SH; Sprenger, Levelt, \& Kempen, 2006). In this model of idiom production, the lexical concept of an idiom is associated with a superlemma at the lexical syntactic level - that is, the representation of the syntactic properties of the idiom connected with the lemmas of its constituent parts (see Figure 1). The superlemma mediates between an idiom's lexical conceptual representation and the lemmas of its individual words. It specifies the syntactic relationships between the individual lemmas that constitute the idiomatic expression and disables the operations not accepted by it. For example, the superlemma of kick the bucket will disable its use in the passive form.

When an idiom is to be produced, the model assumes that activation spreads from the lexical concept to the superlemma, and superlemma selection is a condition on the activation spreading to simple lemmas.

As noted, the SH is a model of idiom production, and the processes leading to the comprehension and production of these expressions are likely to be very different. However, assuming that the same concepts and linguistic representations are used in language comprehension and production (Roelofs, 2003), the problem of how idioms are represented in the mental lexicon is shared by both theories of comprehension and production. And indeed, the superlemma model can also be read, from input to concepts, as an account of idiom comprehension. In this case, simple lemmas must first be activated by the linguis- tic input. They activate their conceptual lexical nodes and the superlemma, which, in turn, activates its corresponding lexical conceptual node, whose activation builds up until it exceeds some critical threshold. At that point, the idiom is recognized.

As Sprenger et al. (2006) point out, the SH is generally compatible with the $\mathrm{CH}$, with one difference: According to the $\mathrm{SH}$, the activation of an idiom's concept builds up in a continuous fashion, starting from the initial activation of its first lemma, and the idiom is recognized when the activation of the concept rises over the threshold. In contrast, the $\mathrm{CH}$ assumes that idiom activation is not a continuous process, and does not occur until special elements in an idiom (the idiom key) have been recognized. There are findings in the literature supporting the claim that activation does not spread up to idiom concepts starting from string onset (Tabossi et al., 2005; Tabossi \& Zardon, 1993, 1995). However, the present evidence does not discriminate between the two alternatives, and it is compatible with both models.

In fact, like the $\mathrm{CH}$, the $\mathrm{SH}$ does not discriminate between decomposable and nondecomposable idioms and assumes that idiomatic strings undergo linguistic analysis like any other piece of language. Hence, it does not assume that there is something special in the processing of idioms with respect to other expressions, including literal expressions; and, in order to explain the idiom superiority effect, it must rely on a general mechanism that applies to idioms as much as it does to other strings of comparable characteristics. In this perspective, the finding that decomposable idioms, nondecomposable idioms, and clichés are equally fast with respect to matched novel expressions is perfectly compatible with this theory.

Our findings are also compatible with models not specifically concerned with idiom processing but devoted to characterizing the organization of the mental lexicon so as to account for people's use of formulaic language. In the heteromorphic distributed lexicon (HDL; Wray, 2002) the lexicon is seen as being made up of five lexicons 
characterized by the functions each of them serves. One store contains units that serve a grammatical role and are employed in the generation of novel sentences (e.g., the, and, in order to); another store contains referential expressions, including mono- and polymorphic words (e.g., $d o g$, fearfully) and word strings such as idioms (e.g., pull someone's leg). Items in this lexicon are also used to produce novel sentences. The third lexicon contains contextdependent words (e.g., careful!) and expressions (e.g., get out of my way!) that show little creativity and are used more for communicative than for referential purposes. The fourth lexicon contains memorized texts. Finally, the fifth lexicon contains units used as automatic responses to external or psychological stimuli (e.g., what?; my goodness!). Each of these stores contains three types of holistic units: morphemes, words, and word strings, all of which are assumed to be stored and processed holistically.

An important aspect of the HDL is that most units are represented multiple times. For example, take it slowly may be stored holistically in the lexicon containing expressions used for communicative purposes, whereas take, slow, and slowly can be stored in the referential lexicon, and it and -ly can be stored in the lexicon containing units that serve grammatical purposes. The utility of a similar representation is that when analytic processing is not needed, take it slowly can be processed holistically, and only when necessary is it fully analyzed.

The HDL can easily account for the present results. In a task like the semantic judgment task employed here, all the conventional strings are presented in their citation form, and there is no need for them to be analytically processed. They are known to participants and all that is needed to perform the task is to retrieve the expressions as units from the lexicon. This gives them a processing advantage over novel control expressions that are not stored in the lexicon and must be analyzed. The HDL is reminiscent of the LRH in that it posits a contrast between retrieval and computing processes but, unlike the LRH, formulae do not need to be noncompositional to be stored in the lexicon; any expression that is conventional in the language is stored.

This perspective stresses the importance of formulae, and emphasizes the processing advantages of prefabricated chunks in language use - in particular, from the point of view of the speaker. But as appealing as it may be, several pieces of evidence suggest that it may not be correct. First of all, it has been often observed that that syntactic analysis is compulsory and automatic (Boland, Tanenhaus, \& Garnsey, 1990; Miller \& Johnson-Laird, 1976; Stroop, 1935; Trueswell \& Kim, 1998). In other words, it cannot simply be suspended when more "economic" strategies, such as retrieval, are available.

Also, there is evidence that individual words are retrieved in idiomatic expressions, as they are in literal language. Van de Voort and Vonk (1995) conducted a crossmodal study in which participants were auditorily presented with incomplete sentences that contained a predictable idiomatic expression (e.g., John let the cat out of the) or a matched literal control (e.g., John put his things in a). At the end of the auditory prime, they were presented with a picture representing the last word of the idiom (e.g., the picture of a bag). Their task was to name the picture (e.g., "bag"). The results showed that naming was faster in the idiomatic than in the literal context. The authors dismissed the notion that the effect was phonological, and concluded that the only reason picture naming was facilitated in the idiomatic context was that the literal meaning of the last word of the idiom had been accessed during string processing.

A further line of studies indicates that even idioms, whose meaning is certainly stipulated, undergo full syntactic analysis and are not treated as units. Using a sentence-priming procedure, Peterson et al. (2001) had their participants hear sentence primes ending with incomplete idioms. Sentences were biased toward a literal (e.g., the soccer player slipped when tried to kick the ...) or idiomatic (e.g., the man was old and feeble and it was believed that he would soon kick the ...) completion. At the end of the sentence fragment, a visual target was presented on a computer screen. Participants had to name the target as quickly as possible. Target words were always semantically unrelated to the contexts, but could be syntactically appropriate - for instance, a noun (e.g., town) — or inappropriate - for instance, a verb (e.g., grow). For both types of sentences, responses were faster in the syntactically appropriate than in the inappropriate condition. The effects were similar to those observed with literal sentences, and held with target words as well as nonwords. These findings suggest that the syntactic structures of idiomatic strings are derived during online comprehension, even though they cannot deliver the meanings of these expressions.

In a similar vein, in Cutting and Bock (1997) participants read two simultaneously presented phrases and, after a delay, produced one of them in response to a cue. The procedure was intended to elicit spontaneous blends. The phrases were idioms and nonidioms varying in syntactic and semantic similarity. The results showed that structural rather than meaning similarities increased blend production, regardless of idiomaticity, suggesting that idioms are syntactically analyzed and produced just like nonidiomatic phrases.

More recently, using a syntactic priming paradigm, Konopka and Bock (2009) examined the effectiveness of phrasal verbs in inducing structural generalization. Phrasal verbs were idiomatic (e.g., put up) or nonidiomatic (e.g., send in). Participants recalled sentences they had read in rapid serial presentation. Prime and target sentences contained phrasal verbs with particles preceding or following the direct object (e.g., put up some of the refugees and put some of the refugees up). The results showed that particle placement in the repeated sentences was equally primed by idiomatic and nonidiomatic verbs, both of which induced structural generalization. These results strongly argue for the syntactic compositionality of idiomatic expressions, suggesting that they undergo the same structural processing as literal expressions.

Taken together, these findings indicate that idiomatic expressions are not treated holistically; rather, they undergo full analysis, like literal expressions. This is the 
case even though they are semantically noncompositional. A fortiori, it is reasonable to assume that clichés, which are fully compositional, are also analyzed, and are not recognized through holistic processes. But if the difference between holistic and analytic processes cannot be invoked, why are conventional expressions recognized faster than their literal counterparts are? This study indicates that the explanation rests on familiarity: Familiar objects, including linguistic objects, are processed faster than novel ones are, and the effect observed with conventional multiword expressions is just another instance of this general phenomenon.

\section{AUTHOR NOTE}

R. Fanari is now at the University of Cagliari, Cagliari, Italy, and $\mathrm{K}$. Wolf is now at the Department of Mental Health in Trieste, Italy. The research was supported by PRIN 2005. We thank Corrado Cavallero and Giuseppe Longobardi for their valuable suggestions. Correspondence concerning this article should be addressed to P. Tabossi, Dipartimento de Psicologia, University of Trieste, Via S. Anastasio 12, 34134 Trieste, Italy (e-mail: tabossi@units.it).

\section{REFERENCES}

Boland, J. E., Tanenhaus, M. K., \& Garnsey, S. M. (1990). Evidence for the immediate use of verb control information in sentence processing. Journal of Memory \& Language, 29, 413-432.

Bortolini, U., Tagliavini, C., \& Zampolli, A. (1972). Lessico di frequenza della lingua italiana contemporanea. Milan: Garzanti.

BuRT, J. S. (1992). Against the lexical representation of idioms. Canadian Journal of Psychology, 46, 582-605.

CACCIARI, C., \& TABOSSI, P. (1988). The comprehension of idioms. Journal of Memory \& Language, 27, 668-683.

CAillies, S., \& Butcher, K. (2007). Processing of idiomatic expressions: Evidence for a new hybrid view. Metaphor \& Symbol, 22, 79-108.

Caillies, S., \& Le Sourn-Bissaoui, S. (2006). Idiom comprehension in French children: A cock-and-bull story. European Journal of Developmental Psychology, 3, 189-206.

CASAdeI, F. (2001). Breve dizionario di linguistica. Rome: Carocci.

Connine, C. M., Mullennix, J., Shernoff, E., \& Yelen, J. (1990). Word familiarity and frequency in visual and auditory word recognition. Journal of Experimental Psychology: Learning, Memory, \& Cognition, 16, 1084-1096.

Cronk, B. C., Lima, S. D., \& Schweigert, W. A. (1993). Idioms in sentences: Effects of frequency, literalness, and familiarity. Journal of Psycholinguistic Research, 22, 59-82.

Cronk, B. C., \& Schweigert, W. A. (1992). The comprehension of idioms: The effects of familiarity, literalness, and usage. Applied Psycholinguistics, 13, 131-146.

CutTing, J. C., \& Bock, K. (1997). That's the way the cookie bounces: Syntactic and semantic components of experimentally elicited idiom blends. Memory \& Cognition, 25, 57-71.

GERNSBACHER, M. A. (1984). Resolving 20 years of inconsistent interactions between lexical familiarity and orthography, concreteness, and polysemy. Journal of Experimental Psychology: General, 113, 256-281.

GibBS, R. W., JR. (1980). Spilling the beans on understanding and memory for idioms in conversation. Memory \& Cognition, 8, 149-156.

GibBs, R. W., JR., NAYAK, N. P., Bolton, J. L., \& Keppel, M. E. (1989). Speakers' assumptions about the lexical flexibility of idioms. Memory \& Cognition, 17, 58-68.

Gibbs, R. W., JR., Nayak, N. P., \& CutTing, [J.] C. (1989). How to kick the bucket and not decompose: Analyzability and idiom processing. Journal of Memory \& Language, 28, 576-593.

Giora, R., \& FeIN, O. (1999). On understanding familiar and lessfamiliar figurative language. Journal of Pragmatics, 31, 1601-1618.

Glass, A. L. (1983). The comprehension of idioms. Journal of Psycholinguistic Research, 12, 429-442.
GLUCKSBERG, S. (2001). Understanding figurative language: From metaphors to idioms. Oxford: Oxford University Press.

JACKENDOFF, R. (1995). The boundaries of the lexicon. In M. Everaert, E.-J. van der Linden, A. Schenk, \& R. Schreuder (Eds.), Idioms: Structural and psychological perspectives (pp. 133-165). Hillsdale, NJ: Erlbaum.

KIRKPATRICK, B. (1996). Clichés: Neither a defence nor a condemnation. English Today, 12, 16-25.

KonOPKA, A. E., \& Bock, K. (2009). Lexical or syntactic control of sentence formulation? Structural generalizations from idiom production. Cognitive Psychology, 58, 68-101.

Mateu, J., \& EsPinal, M. T. (2007). Argument structure and compositionality in idiomatic constructions. Linguistic Review, 24, 33-59.

McGlone, M. S., Glucksberg, S., \& CACCIARI, C. (1994). Semantic productivity and idiom comprehension. Discourse Processes, 17, 167-190.

Miller, G. A., \& Johnson-Laird, P. N. (1976). Language and perception. Cambridge, MA: Harvard University Press.

NunberG, G., SAG, I. A., \& Wasow, T. (1994). Idioms. Language, 70, 491-534.

Ortony, A., Schallert, D. L., Reynolds, R. E., \& Antos, S. J. (1978). Interpreting metaphors and idioms: Some effects of context on comprehension. Journal of Verbal Learning \& Verbal Behavior, 17, 465-477.

Peterson, R. R., Burgess, C., Dell, G. S., \& Eberhard, K. M. (2001). Dissociation between syntactic and semantic processing during idiom comprehension. Journal of Experimental Psychology: Learning, Memory, \& Cognition, 27, 1223-1237.

Popiel, S. J., \& MCRAE, K. (1988). The figurative and literal senses of idioms, or all idioms are not used equally. Journal of Psycholinguistic Research, 17, 475-487.

QuARTu, B. M. (2000). Dizionario dei modi di dire della lingua italiana. Milan: RCS Libri.

RoELOFs, A. (2003). Modeling the relation between the production and recognition of spoken word forms. In N. O. Schiller \& A. S. Meyer (Eds.), Phonetics and phonology in language comprehension and production: Differences and similarities (pp. 115-158). Berlin: Mouton de Gruyter.

Schraw, G., Trathen, W., Reynolds, R. E., \& Lapan, R. T. (1988). Preferences for idioms: Restrictions due to lexicalization and familiarity. Journal of Psycholinguistic Research, 17, 413-424.

SchWeIgerT, W. A. (1986). The comprehension of familiar and less familiar idioms. Journal of Psycholinguistic Research, 15, 33-45.

SCHWEIGERT, W. A. (1991). The muddy waters of idiom comprehension. Journal of Psycholinguistic Research, 20, 305-314.

Schweigert, W. A., Cintron, J., Sullivan, K., Ilic, E., Ellis, S., Dobrowits, C., \& RoberTs, C. (2003). Novel figurative phrases and idioms: Phrase characteristics over multiple presentations. Journal of Psycholinguistic Research, 32, 455-475.

Schweigert, W. A., \& Moates, D. R. (1988). Familiar idiom comprehension. Journal of Psycholinguistic Research, 17, 281-296.

SEARLE, J. (1975). Indirect speech acts. In P. Cole \& J. L. Morgan (Eds.), Speech acts (Syntax and Semantics, Vol. 3, pp. 59-82). New York: Academic Press.

Sprenger, S. A., Levelt, W. J. M., \& Kempen, G. (2006). Lexical access during the production of idiomatic phrases. Journal of Memory \& Language, 54, 161-184.

Stroop, J. R. (1935). Studies of interference in serial verbal reactions. Journal of Experimental Psychology, 18, 643-662.

Swinney, D. A., \& CutLer, A. (1979). The access and processing of idiomatic expressions. Journal of Verbal Learning \& Verbal Behavior, 18, 523-534.

Tabossi, P., Fanari, R., \& Wolf, K. (2005). Spoken idiom recognition: Meaning retrieval and word expectancy. Journal of Psycholinguistic Research, 34, 465-495.

Tabossi, P., Fanari, R., \& Wolf, K. (2008). Processing idiomatic expressions: Effects of semantic compositionality. Journal of Experimental Psychology: Learning, Memory, \& Cognition, 34, 313-327.

TABossi, P., \& Zardon, F. (1993). The activation of idiomatic meaning in spoken language comprehension. In C. Cacciari \& P. Tabossi (Eds.), Idioms: Processing, structure, and interpretation (pp. 145162). Hillsdale, NJ: Erlbaum.

TABossi, P., \& ZARDon, F. (1995). The activation of idiomatic meaning. In M. Everaert, E.-J. van der Linden, A. Schenk, \& R. Schreuder 
(Eds.), Idioms: Structural and psychological perspectives (pp. 273282). Hillsdale, NJ: Erlbaum.

TitonE, D. A., \& Connine, C. M. (1994a). Comprehension of idiomatic expressions: Effects of predictability and literality. Journal of Experimental Psychology: Learning, Memory, \& Cognition, 20, 1126-1138.

Titone, D. A., \& Connine, C. M. (1994b). Descriptive norms for 171 idiomatic expressions: Familiarity, compositionality, predictability, and literality. Metaphor \& Symbolic Activity, 9, 247-270.

Trueswell, J. C., \& Kim, A. E. (1998). How to prune a garden path by nipping it in the bud: Fast priming of verb argument structure. Journal of Memory \& Language, 39, 102-123.

VAN DE VoorT, M. E. C., \& VonK, W. (1995). You don't die immediately when you kick an empty bucket: A processing view on semantic and syntactic characteristics of idioms. In M. Everaert, E.-J. van der Linden, A. Schenk, \& R. Schreuder (Eds.), Idioms: Structural and psychological perspectives (pp. 283-300). Hillsdale, NJ: Erlbaum.

WraY, A. (2002). Formulaic language and the lexicon. Cambridge: Cambridge University Press.

\section{APPENDIX}

Conventional and Control Expressions Used in the Experiment

\begin{tabular}{cc}
\hline Conventional & \\
\hline & Decomposable Idioms \\
Literal
\end{tabular}

Andare in fumo (come to nothing, fall through)

Go up in smoke

Arrivare in porto (get to the end)

Arrive in the harbor

Aspettare al varco (lie in wait; bide one's time)

Wait at the passage

Essere sulle spine (be on tenterhooks)

Be on the thorns

Cambiare disco (change the subject)

Change disk

Prendere la porta (go away)

Take the door

Toccare il fondo (hit bottom)

Touch the bottom

Uscire dal guscio (leave the nest; come out of one's shell)

Come out from the shell

Nonliteral

Calcare la mano (be hard [on someone])

Tread the hand

Confondere le acque (create confusion on purpose)

Confuse the waters

Mettere al tappeto (knock down)

Put to the mat

Mettere in riga (make someone behave properly)

Put in line

Seguire a ruota (follow close behind)

Follow at wheel

Tenere sulla corda (keep on tenterhooks)

Keep on the rope

Trattare coi guanti (treat someone with kid gloves)

Treat with the gloves

Uscire dal seminato (wander off the point)

Go out from the sown field
Guardare il fumo

Watch the smoke

Lasciare il porto

Leave the harbor

Aprire il varco

Open the passage

Avere le spine

Have the thorns

Vendere un disco

Sell a record

Lavare la porta

Wash the door

Mettere in fondo

Put at the bottom

Dare il guscio

Give the shell

Ferire la mano

Wound the hand

Assaggiare le acque

Test the waters

Alzare il tappeto

Lift the mat

Tirare una riga

Draw a line

Cercare la ruota Look for the wheel

Mettere sulla corda

Put on the rope

Pulire coi guanti

Clean with the gloves

Guardare il seminato

Stare at the sown field

Nondecomposable Idioms

Literal

Abbassare la cresta (come off one's high horse)

Lower the crest

Cadere dalle nuvole (to be astonished at something trivial)

Fall from the clouds

Chiudere un occhio (turn a blind eye)

Close an eye

Essere al fresco (be in jail)

$\mathrm{Be}$ at the fresh

Prendere per il naso (hoodwink)

Take by the nose

Scaldare il banco (be lazy at school)

Warm the bench

Tirare la corda (exaggerate)

Pull the rope

Vedere le stelle (feel a strong pain; see stars)

See the stars
Accarezzare la cresta

Pat the crest

Mostrare le nuvole

Show the clouds

Lavare un occhio

Wash an eye

Sentire il fresco

Feel the fresh

Bagnare il naso

Wet the nose

Pulire il banco

Clean the bench

Avere la corda

Have the rope

Guardare le stelle

Look at the stars 
APPENDIX (Continued)

\begin{tabular}{|c|c|}
\hline Conventional & Control \\
\hline \multicolumn{2}{|l|}{ Nonliteral } \\
\hline Andare a genio (be pleasant; be to one's liking) & Essere un genio \\
\hline Go to genius & Be a genius \\
\hline Andare a monte (fail) & Stare sul monte \\
\hline Go to mountain & Be on the mountain \\
\hline Avere polso (be authoritative; be energetic) & Alzare il polso \\
\hline Have wrist & Raise the wrist \\
\hline Cadere a fagiolo (happen at the right moment) & Lavare il fagiolo \\
\hline Fall at bean & Wash the bean \\
\hline Far secco (kill) & Essere secco \\
\hline Make dry & Be dry \\
\hline Prendere sotto gamba (undervalue) & Tenere sulla gamba \\
\hline Take under leg & Take on the leg \\
\hline Scoprire gli altarini (discover skeletons in [someone's] closet) & Pulire gli altarini \\
\hline Uncover the small altars & Clean the small altars \\
\hline Tenere a stecchetto (keep someone short of money or food) & Avere uno stecchetto \\
\hline Keep at small stick & Have a small stick \\
\hline \multicolumn{2}{|l|}{ Clichés } \\
\hline Allacciare le cinture & Accorciare le cinture \\
\hline Fasten the belts & Shorten the belts \\
\hline Anche i ricchi piangono & Anche i forti piangono \\
\hline Even the rich cry & Even the strong cry \\
\hline Brindare alla salute & Educare alla salute \\
\hline To toast to the health & Educate about health \\
\hline C'è posta per te (You've got mail) & C'è merce per te \\
\hline There is mail for you & There are goods for you \\
\hline E'vietato l'accesso (no entry) & E'murato l'accesso \\
\hline The access is forbidden & The access is walled up \\
\hline Il cliente ha sempre ragione & Il parroco ha sempre ragione \\
\hline The customer is always right & The parish priest is always right \\
\hline Indietro non si torna & Talvolta non si torna \\
\hline Back one does not go & Sometimes one does not return \\
\hline La legge è uguale per tutti & La prova è uguale per tutti \\
\hline The law is equal for all & The test is equal for all \\
\hline La seduta è tolta & La chiave è tolta \\
\hline The session is closed & The key is removed \\
\hline Maneggiare con cura & Pareggiare con cura \\
\hline Handle with care & Balance with care \\
\hline Non gettare oggetti dal finestrino & Non mostrare oggetti dal finestrino \\
\hline Do not throw objects from the window & Do not show objects from the window \\
\hline Più bianco non si può & Più sicuro non si può \\
\hline Whiter is not possible & Safer is not possible \\
\hline Poteva andare peggio & Pareva andare peggio \\
\hline It could go worse & It seemed to go worse \\
\hline Svoltare a destra & Sostare a destra \\
\hline Turn right & Stop on the right \\
\hline Vinca il migliore & Entri il migliore \\
\hline May the best [person] win & May the best come in \\
\hline Vissero felici e contenti & Risero felici e contenti \\
\hline They lived happy and content & They laughed happy and content \\
\hline
\end{tabular}

(Manuscript received May 2, 2008;

revision accepted for publication January 14, 2009.) 